\title{
Living Near an Immigration Detention Center: Impact on Latinas' Health
}

\author{
Maud Joachim-Célestin ${ }^{1}\left[\right.$ [ $\cdot$ Raveena Chara ${ }^{1} \cdot$ Susanne B. Montgomery ${ }^{1}$
}

Accepted: 18 May 2021 / Published online: 7 June 2021

(c) The Author(s), under exclusive licence to Springer Science+Business Media, LLC, part of Springer Nature 2021

\begin{abstract}
There is ample evidence that exposure to Immigration and Customs Enforcement (ICE) activities could widen Latinas' health disparities. Whether or not residing near an ICE detention center (IDC) further impacts their health is unknown. During nationwide increased ICE activities Latinas $(\mathrm{N}=45)$ attended an intervention at two separate sites: one near and another one far from an IDC. A focus group discussion and an interview were conducted using a grounded theory approach. Quantitative data were collected and analyzed. Participants residing near an IDC benefited less from the intervention and reported changes in anxiety levels and in mobility, and a sense of powerlessness. They also requested resources to respond to ICE overreach and broadcasting of their reality. Our results suggest that proximity to IDCs impacts immigrant communities and public health programming, which is inevitably embedded in political realities. These need to be addressed when providing much needed interventions.
\end{abstract}

\section{Background}

In the United States (U.S.) Latinos experience disproportionate health disparities. Of the 34.2 million with diabetes, Latinos remain among the most affected groups [1]. Compared to non-Hispanic whites, they have a greater prevalence of diabetes (17 vs. 8\%) and experience more complications and deaths [2, 3]. Latino health disparities also are evident during the coronavirus pandemic: while representing only $18 \%$ of the U.S. population, $38 \%$ of Latinos have coronavirus disease 2019 (COVID-19) [4], and in California, where $38.9 \%$ of the population is Latino, they account for $58.5 \%$ of COVID-19 cases and 46.8\% of COVID-19-related deaths [5]. We now have evidence that this disparity is related to structural factors, such as social determinants of health (e.g., disproportionate occupational exposure to COVID-19, household density), and to higher rates of conditions associated with COVID-19 complications, such as obesity [6-8]. Indeed, Latino women (Latinas) have one of the highest rates of obesity in the U.S. (78.8\% are overweight or obese), regardless of age [9-11]. However, even when offered access to weight management programs, they are less likely to

Maud Joachim-Célestin

mcelestin@llu.edu

1 School of Behavioral Health, Loma Linda University, 11065 Campus Street, Loma Linda, CA 92350, USA participate in lifestyle-related interventions and, when they participate, are less likely to complete the programs and be successful. Overcoming barriers to successful engagement and completion of lifestyle interventions is especially critical and consequential for the already disenfranchised and often underinsured Latinos [12].

For undocumented Latinos, these disparities are amplified by poor mental health, increased substance use, more isolation, lack of health insurance, and less use of healthcare and social services even when they have access to care [13-16]. These behaviors and conditions, several of which appear to be associated with living with the constant fear of deportation, could potentially be aggravated by news of immigration-related raids and arrests [17].

Worldwide, policies and increased rhetoric promoting intolerance toward immigrants are known to negatively impact their health $[18,19]$. In the U.S. few national events have produced such steep spikes in the incidence of mental and physical conditions of Latino immigrants as immigration raids [20]. In recent years the U.S. administration's aggressive Immigration and Customs Enforcement (ICE) activities, deportations separating parents and children [21], and even detention of Latino-looking U.S. citizens have been documented. Widespread broadcasting of these ICE activities has fostered increasing fear and distrust of law-enforcement entities and distress among many [22-25]. 
As of 2020, the U.S. has the world's largest infrastructure for detaining undocumented immigrants, with immigration detention centers (IDCs) among the nation's fastest growing prison industries [26]. Detention and correctional facilities tend to be placed in rural locations and are often located in neighborhoods where racial and ethnic minorities reside [27-31]. For example, detention facilities in Elizabeth, NJ, Houston, TX, Del Rio, TX, and Albuquerque, NM are in zip codes where Latinos comprise more than $50 \%$ of the population. Thus, it is not unusual to have Latino immigrants - both documented and undocumented-living near IDCs and constantly exposed to visual reminders of ICE activities (ICE buildings, buses and law enforcement agents driving by with arrested immigrants in view), as is the case in the rural town where this study was conducted. The facility in this study is located in a zip code reporting $100 \%$ of residents being Latinos. Residents are exposed regularly to white ICE buses displaying the words "Homeland Security" with the associated blue $\log 0$, which are clearly distinguishable from other buses [32,33]. Aside from the stress of living in the U.S. unauthorized, it is conceivable that the sight of these buses, and the close proximity to the IDCs, could trigger even more distress [34].

While some municipalities welcome correctional facilities as sources of revenue [35, 36], individuals residing near those facilities report fear of losing property value [37], and most consider their proximity undesirable, sometimes even feeling stigmatized for living nearby [38]. Not surprisingly, employees and healthcare providers living and working near IDCs have expressed frustration and a heavy emotional burden as they have witnessed the impact on the Latino communities they serve [39-41]. Yet little is known about the impact on the health of Latinos living near IDCs. With plans to expand some of the IDCs in the country, including the one in Adelanto [42], CA, where this study took place, our findings and recommendations may be particularly timely.

\section{Theoretical/Conceptual Framework}

Immigration arrests or "raids" occur unexpectedly where individuals live or work, and are usually conducted by heavily militarized agents, often leading to post-traumatic stress symptoms among those experiencing or witnessing these events [43, 44]. Moreover, individuals can be susceptible to traumatic stress when continuously exposed to reminders of potential threats, even without ever experiencing them. Symptoms similar to those manifested in post-traumatic stress disorder are likely and are reported to be worse among women than men [45]. The resulting condition, coined "continuous traumatic stress disorder" (CTSD) by Frank Chikane in 1986 [46], is frequently experienced by systematically oppressed and marginalized communities that are unable to benefit from an "external protection" system [47-49]. Continuous traumatic stress has been defined as a series of "emotional or behavioral responses to actual or current danger that the narrator describes as resulting from living under conditions of ongoing danger" [50]. In this case, the sight of reminders of possible threats could lead to a state of hypervigilance in anticipation of a traumatic event. This chronic exposure to threats and risks, perceived vulnerability, and lack of control can eventually bring about depression, learned helplessness, and their associated effects [51]. Based on the previous information, it is conceivable that living with the constant threat of deportation could lead undocumented Latinos, and even more so Latinas, to experience behavior changes associated with CTSD.

The purpose of this study was to assess differences in completion and outcomes of a health promotion program for Latinas based on their intervention group's relative geographic proximity to an IDC. By doing so, we hope to fill an important gap in the literature and provide critical information to help healthcare providers and policy-makers better address the needs of Latinas. We hypothesized that news of immigration arrests would affect attendance and outcomes of a health promotion program for Latinas living near IDCs, in particular those undocumented, more than those of participants living farther away, and that the impact may be associated with symptoms of continuous traumatic stress.

\section{Methods}

\section{Participants}

This mixed-methods study was conducted as part of the evaluation of Full Plate Living, a lifestyle-based weight management and diabetes prevention program for Latinas residing in the Inland Empire (Southern California), an area with a high proportion of Latinos [52, 53]. As part of a larger study, the eight weekly program sessions were delivered in Spanish to 53 women self-identifying as "Latina". Of these, 21 resided within 15 miles of an IDC (Near-IDC group) and 32 lived much farther away (approximately 60 miles away-at least $1 \mathrm{~h}$ away by car during hours of normal traffic) from an IDC (Far-IDC group). While the program was free, participants completed informed consent forms in Spanish or English, and received a $\$ 10$ gift certificate to a local grocery store as incentive for completing each survey and participating in the focus group discussion. Ethical approval for this study was obtained from the Loma Linda University Institutional Review Board (IRB \#5180068). 


\section{Setting: The Detention Center}

The Adelanto ICE detention center is the largest IDC in the U.S. and is located in a rural, predominantly Latino area, four miles from the Latino church building where the intervention was delivered. The associated ICE processing center is only 2.5 miles away. As of June 2020, this IDC has housed nearly 2,000 immigrants [54], and ICE buses can be seen going to and from this facility carrying detained immigrants.

\section{Data Collection}

Quantitative data were collected as part of our ongoing evaluation of the Full Plate Living program, an intervention described in a separate document (Appendix A). Prior to and immediately after program completion, participants completed a standardized set of biometric measures and self-report surveys in Spanish, which included demographic information and assessed relevant behaviors, mental health, and perceived social support. The program was facilitated by trained bilingual community health workers, and data were collected and entered by research assistants.

\section{Qualitative Procedures}

As part of the process evaluation we observed an unexpected attendance drop in our Near-IDC group, formerly one of the most engaged groups. We then conducted a follow-up qualitative exploration using a grounded theory approach by Charmaz [55] guided by the continuous traumatic stress theory. The resulting semi-structured guide was used to explore the reasons for the significant drop in attendance during a focus group discussion (FGD) with a purposive sample of Latinas living near an IDC $(\mathrm{N}=10)$, and a key informant interview (KII) with a community health worker (CHW) who facilitated the program. Probes were used to expand the exploration and allow new issues to emerge (see Appendix B for the interview and focus group guides). The FGD and KII explored two main topics: (1) the effects of ICE-related activity on program participants and the local Latino community, and (2) proposed solutions to counteract or mitigate the deleterious impact of ICE activity, if any. Both the FGD and KII were conducted in Spanish on August 7, 2019, six weeks after program completion and one day after the nationally publicized (and locally much discussed) Mississippi ICE raid where 600 immigrants were arrested, resulting in an increase in fear of deportation among Latinos throughout the nation [56]. Of note, around the same time period residents spoke of a local church raid, which further deepened the discussions about everyone's fear of raids and deportation. The FGD and KII were conducted by a bilingual researcher, audio-recorded with participants' permission, and transcribed by a bilingual translator. A team of two researchers then independently coded the transcripts using emergent thematic coding [57]. The team met to compare the codes, and a third independent researcher facilitated code discrepancy discussions. Once the team agreed to a final codebook, it was applied to code the text.

\section{Quantitative Measures and Analyses}

\section{Biometric Measures}

Height and weight were measured using a Seca portable stadiometer (Seca North America, Chino, CA) and InBody 270 scale (InBody USA, Cerritos, CA), with a person standing without shoes or heavy clothing. Results were reported in inches and pounds (lbs), respectively.

Body mass index (BMI) was calculated as weight $\times 703 /$ (height $)^{2}$ and reported in $\mathrm{kg} / \mathrm{m}^{2}$. Overweight was defined as BMI between 25 and $29.9 \mathrm{~kg} / \mathrm{m}^{2}$, and obesity as BMI $>30 \mathrm{~kg} / \mathrm{m}^{2}$.

\section{Self-Reported Measures}

Demographics: we assessed age (years), relationship status ( 4 categories), household size $(1=$ living alone; $5=$ at least 5 persons $)$, number of children in the home $(0=$ none; $5=5$ or more children), participants' education level $(1=$ no formal education; 2 to $7=$ increasing levels of education), employment status (no/yes), and annual family income (5 categories).

Immigration status: due to the highly sensitive nature of the issue, and out of concern for participants' safety, individuals' immigration status was not collected as part of the quantitative data. After much discussion, and with the advice of our CHWs, the decision was made to ask participants to state only their nativity $(1=$ United States, $2=$ Mexico, $3=\mathrm{Central} /$ South America, $4=$ Caribbean) and the length of time living in the U.S. We then analyzed the data comparing individuals born in the U.S. and those not born in the U.S. The variable was coded immigration/nativity to indicate that the latter group immigrated (regardless of legality).

Food insecurity was assessed based on the response $(0=$ never true, $1=$ sometimes true, $2=$ often true $)$ to the following two statements: "Within the past 12 months we worried whether our food would run out before we got money to get more" and "Within the past 12 months we didn't have money to get more food".

Dietary patterns and physical activity (short international physical activity questionnaire [58]) were assessed using a flipchart with pictures of locally available foods (fruits, vegetables, legumes, grains, etc.) to assess food frequency ( $1=$ once a day; $4=4$ or more times) and pictures of exercise types; lower numbers meant less consumption/activity. 
Social support for healthy behaviors, such as engagement in physical activity and healthy food consumption (fruits, vegetables, low-fat, low-sugar, low-salt food), was assessed using a 6-point Likert scale.

Depression and anxiety were assessed with the PHQ-9 scale [59] and the GAD-7 scale [60], respectively.

We used SPSS, v.25 for quantitative analyses, including attrition analyses and group comparisons (BMI, demographics, behavior, mental health, and familial support). Food insecurity and employment status comparisons were made using chi-square tests, significance was assessed with independent $t$ tests, and intervention effects were analyzed using paired $t$ tests.

Transcripts were analyzed for emergent themes supported by critical quotes using the 2017 computer software program $\operatorname{MAXQDA}^{\circledR}$ (v.12, Berlin, GDR) [61], and then quotes were translated from Spanish to English.

\section{Results}

\section{Quantitative Analyses Results}

Table 1 compares baseline characteristics of participants from the Near-IDC group with those from the Far-IDC group. Average participant age was $47( \pm 14)$ years, and most participants were married and immigrants born in Mexico. Participants in the Near-IDC and Far-IDC groups were comparable in age, marital status, BMI, birth country, years of residence in the U.S., educational level, family income, food insecurity status, number of meals per day, depression, and anxiety. The Near-IDC group differed from the Far-IDC group in that, at baseline, they reported more walking $(p=0.03)$ and vegetable consumption $(p=0.01)$ and perceived more social support for healthy eating $(p=0.007)$ and for physical activity $(p=0.000)$. Near-IDC group participants were also more likely to be unemployed $(p=0.01)$.

Attrition, defined as missing more than two sessions including the last session, was significantly higher in the Near-IDC group (51\% of enrollees) than in the Far-IDC group ( $25 \%$ of enrollees; $p=0.01$ ). Completion was defined as attending at least six sessions including the last session. When comparing "completers" with those who dropped out ("dropout group") within each location, attrition analyses revealed no baseline differences between the dropouts and completers within the Far-IDC group. However, several differences existed between Near-IDC dropouts and completers: completers were more likely to receive social support for physical activity $(p=0.001)$, tended to eat more frequently during the day $(p=0.053)$, and tended to be born in the U.S. In fact, all Near-IDC dropouts were foreign-born $(p=0.055)$.
Figure 1 depicts the timing of increased immigration activities and attendance changes among Near-IDC participants. Approximately a week into the program, President Trump's rhetoric against California and his stance toward immigrants grew more intense, with threats of raids highly publicized [62] as he ordered that buses drop off undocumented immigrants in Southern California [63]. On the very day that Latino immigrants were dropped off, attendance decreased by a third, and by the time the program ended, half of the participants had stopped attending.

Table 2 shows within- and between-group differences at program completion. When comparing completers in both groups, Near-IDC completers continued to report more vegetable consumption and perceived more emotional support for healthy behaviors than Far-IDC completers. Yet, when comparing program results between groups, those who remained in the Near-IDC group seemingly benefited less from the intervention than participants who completed the program in the Far-IDC group. In contrast with the FarIDC group, Near-IDC overweight and obese participants had a non-statistically significant trend toward weight gain, with $60 \%$ gaining weight and $40 \%$ losing weight. Far-IDC overweight and obese participants had a mean weight loss of $2 \pm 4.2 \mathrm{lbs}(p=0.04)$, and $76 \%$ of them lost weight. At program completion the Far-IDC group reported less consumption of unhealthy food and sugar-sweetened beverages ( $p=0.009$ and $p=0.002$, respectively), more fruit consumption ( $p=0.007)$, more walking $(p=0.02)$, and more vigorous physical activity $(p=0.02)$ compared to baseline. Meanwhile, Near-IDC group completers reported improvement in only two behaviors: vegetable consumption $(p=0.047)$ and moderate activity $(p=0.049)$. Vegetable consumption group differences remained statistically significant $(p=0.02)$. The Far-IDC group reported more social support by program completion, with support for physical activity $(p=0.056)$ approximating statistical significance. Although the NearIDC group continued to report more social support for healthy behaviors than the Far-IDC group at the end of the program, they experienced a non-statistically significant downward trend in social support. Last, while the Far-IDC group had a statistically significant decrease in both depression and anxiety levels $(p=0.004)$, neither the reduction in anxiety nor in depression was statistically significant in the Near-IDC group.

\section{Qualitative Data Results}

Table 3 describes the five qualitative themes that emerged when we contextually explored the impact of increased ICE activity and the disproportional dropout in the Near-IDC group: (1) high program attrition; (2) sadness, fear, anxiety, and stress; (3) reduced mobility; (4) reduced local retail and commercial activity; (5) request for word about their plight 


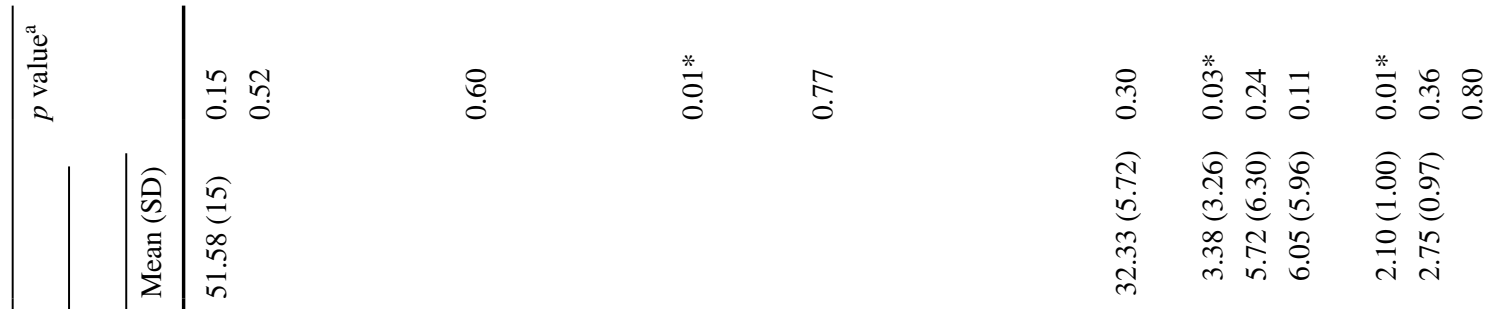

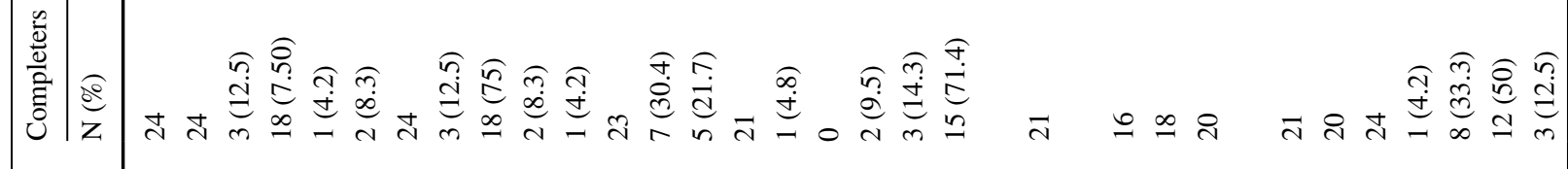

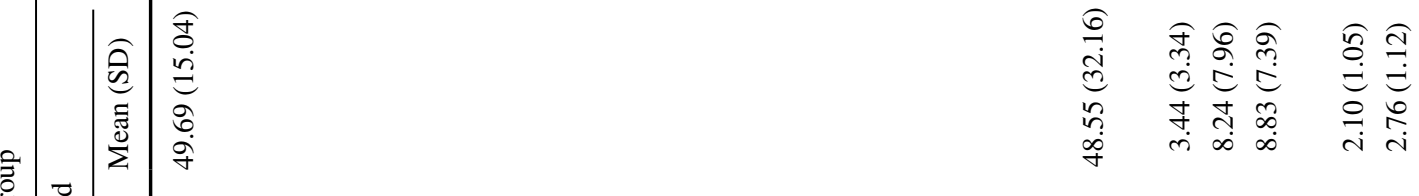

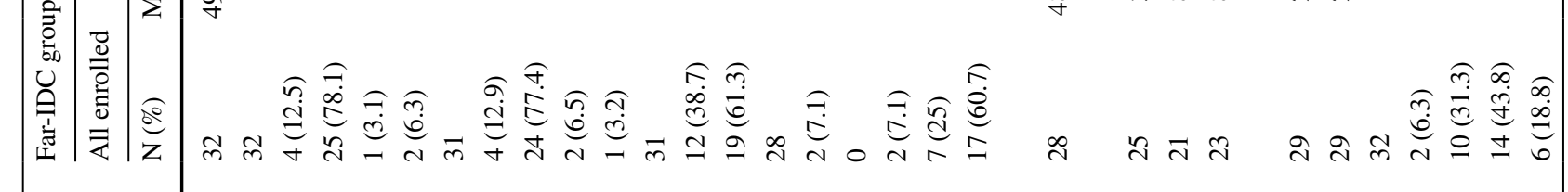

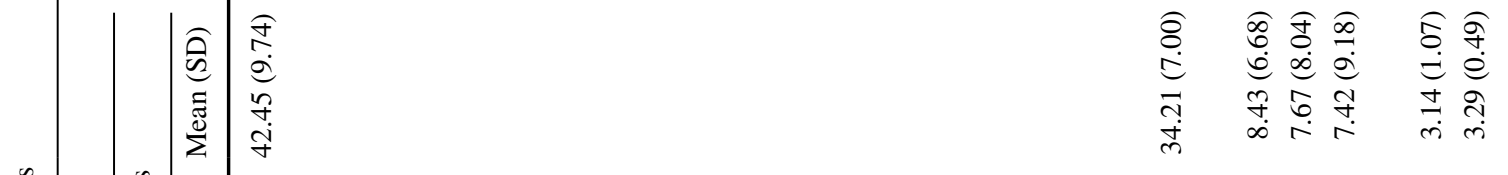

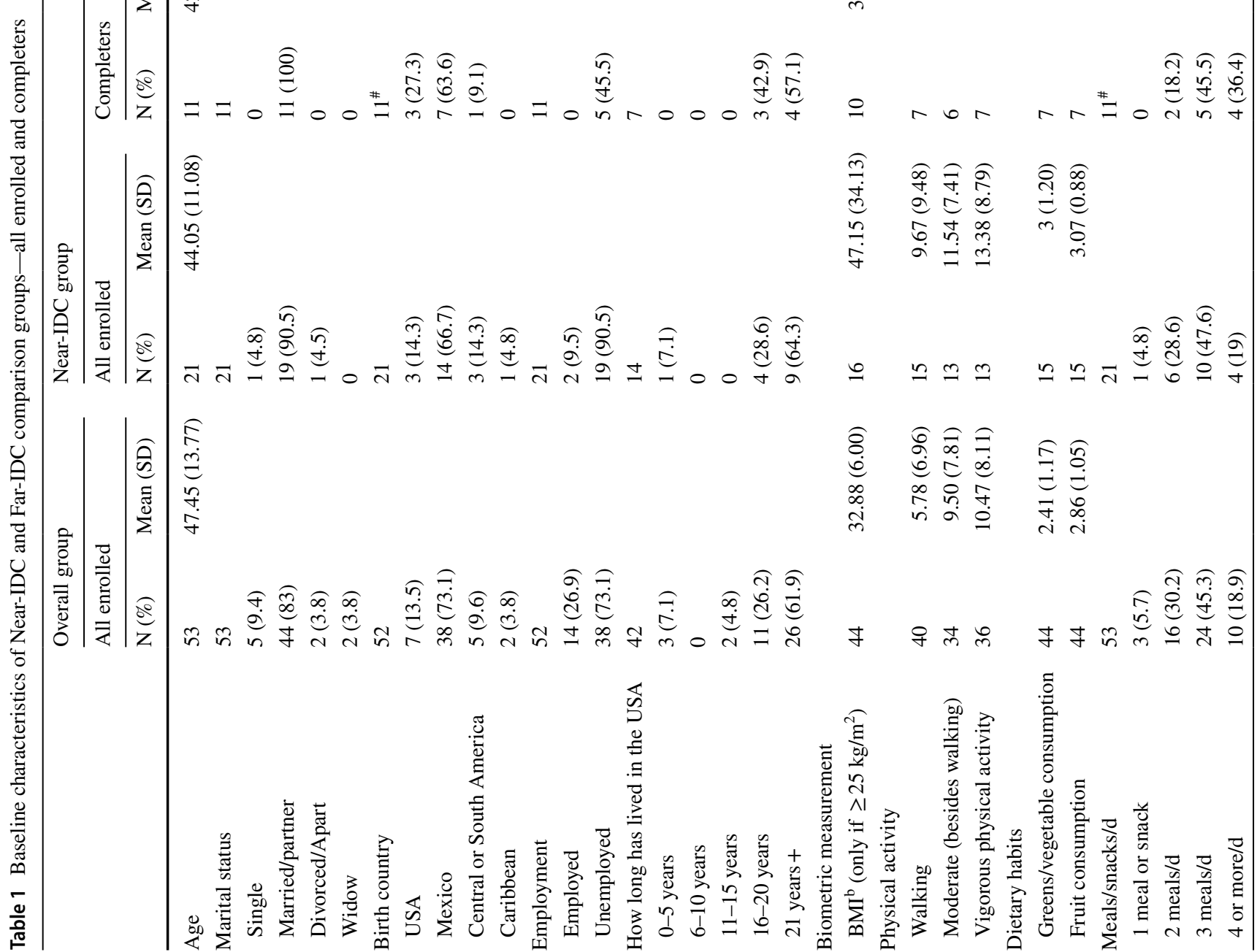




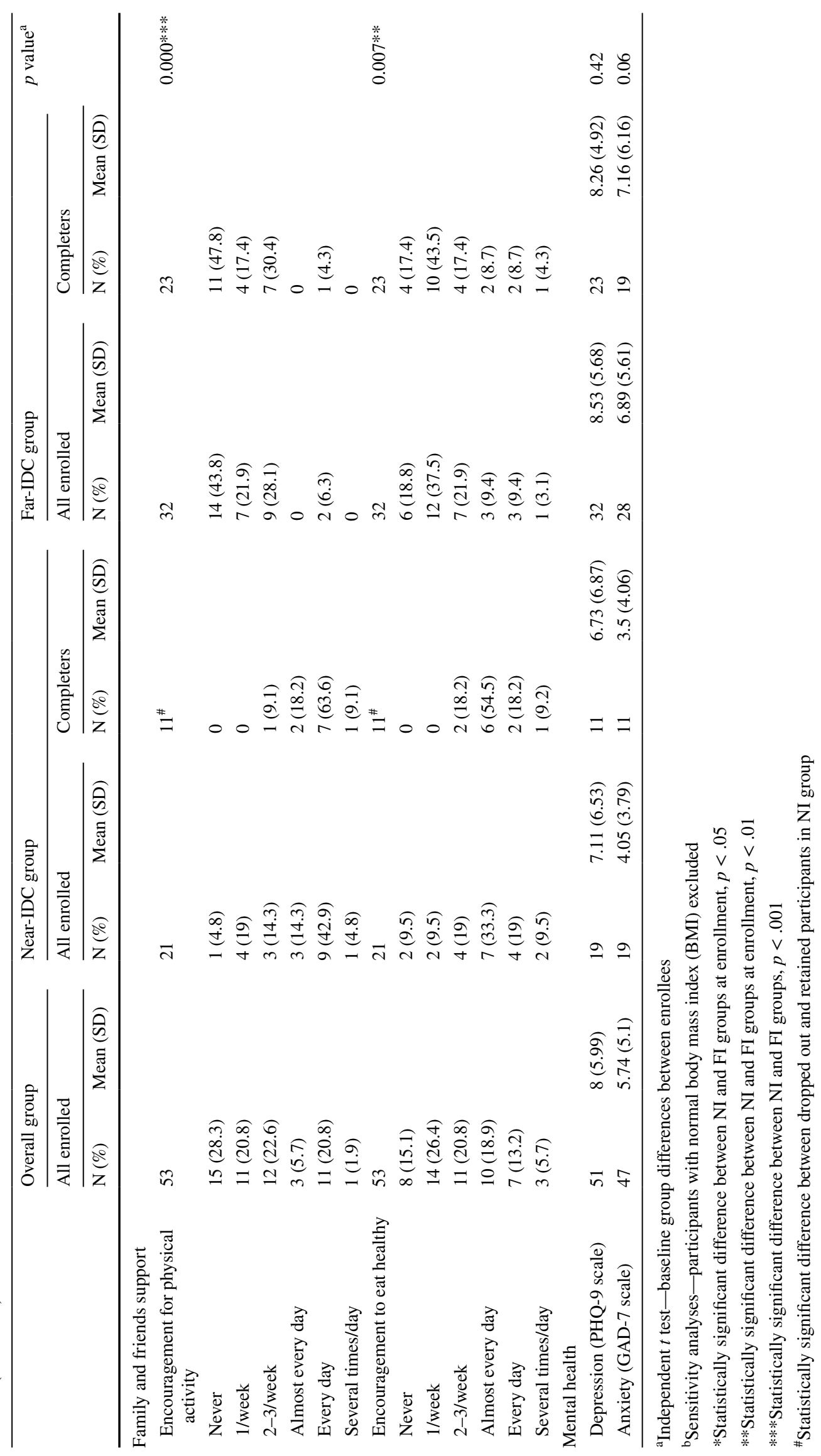




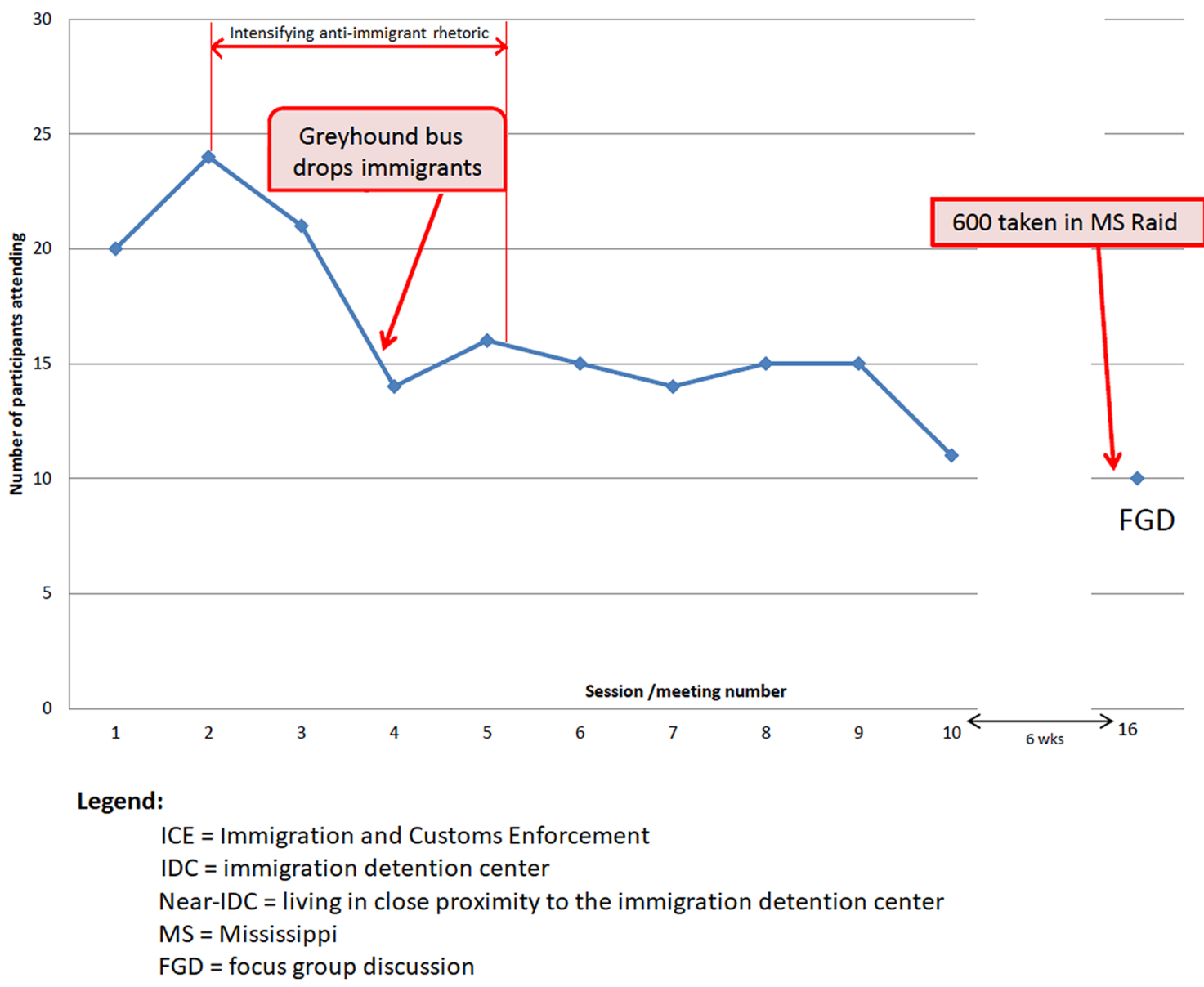

Fig. 1 Timing of ICE activity and changes among Near-IDC participants

to be spread and for tools/resources for self-protection. Briefly, participants shared that the heightened ICE activity in their community resulted in sadness and high anxiety/ depression levels, fear of being separated from their children and other family members, and a feeling of disappointment. This in turn resulted in social withdrawal (regardless of immigration status), including limiting all non-essential activities to avoid putting their loved ones at risk of deportation. Some expressed a renewed determination to stand up against the intimidation, while others expressed a sense of helplessness. Still, they requested and hoped to receive tangible help to address the unanticipated, chilling effects of the ICE activities, as they-including U.S. citizens—did not know how to deal with ICE confrontations.

\section{Discussion}

Although our research was not originally designed to investigate the impact of living near an IDC on Latinas, drastic changes were observed in group dynamics and program results when delivering our health promotion program, which coincided with heightened nationwide ICE activity. The authors decided to compare attendance and program results with those of another group that attended the same program more than $1 \mathrm{~h}$ away by car from an IDC facility. In addition, we qualitatively explored whether and how differences related to people's relative proximity to an IDC and legal status affected outcomes. The comparison group was similar in education level, income, food insecurity, and 
Table 2 Intervention effects (pre-post changes) in Near-IDC (NI) and Far-IDC (FI) groups

\begin{tabular}{|c|c|c|c|c|c|}
\hline Measures & $\mathrm{N}$ & Baseline mean (SD) & 3 months mean $(\mathrm{SD})$ & Independent $t$ test ${ }^{\mathrm{a}}$ & $\begin{array}{l}\text { Paired } t \text { test } \\
\text { mean (SD) }\end{array}$ \\
\hline \multicolumn{6}{|l|}{ Biometric measurements } \\
\hline Body mass index ${ }^{\mathrm{b}}-\mathrm{NI}$ & 10 & $34.21(7)$ & $34.93(7.24)$ & 0.43 & 0.47 \\
\hline Body mass index ${ }^{\mathrm{b}}$-FI & 21 & $32.33(5.71)$ & $31.94(5.73)$ & & $0.03 *$ \\
\hline \multicolumn{6}{|l|}{ Physical activity } \\
\hline Walking-NI & 7 & $8.43(6.68)$ & $12.43(8.94)$ & $0.052^{\dagger}$ & 0.17 \\
\hline Walking-FI & 16 & $3.38(3.26)$ & $8.00(7.31)$ & & $0.02 *$ \\
\hline Moderate (besides walking)—NI & 6 & $7.67(8.04)$ & $13.17(7.96)$ & 0.16 & $0.049^{*}$ \\
\hline Moderate (besides walking-FI & 18 & $5.72(6.30)$ & $8.22(8.39)$ & & 0.19 \\
\hline Vigorous physical activity-NI & 7 & $7.43(9.18)$ & $10.71(9.84)$ & 0.17 & 0.44 \\
\hline Vigorous physical activity-FI & 20 & $6.05(5.96)$ & $9.20(7.84)$ & & $0.02 *$ \\
\hline \multicolumn{6}{|l|}{ Dietary patterns } \\
\hline Greens/vegetables consumption-NI & 5 & $3.14(1.07)$ & $3.57(1.13)$ & $0.02 *$ & 0.29 \\
\hline Greens/ vegetables consumption-FI & 21 & $2.10(1.00)$ & $2.57(0.75)$ & & $0.047 *$ \\
\hline Fruit consumption-NI & 7 & $3.29(0.49)$ & $3.71(0.95)$ & 0.97 & 0.08 \\
\hline Fruit consumption-FI & 20 & $2.75(0.97)$ & $3.35(0.75)$ & & $0.007 * *$ \\
\hline \multicolumn{6}{|l|}{ Family and friends support } \\
\hline Encouragement for $\mathrm{PA}^{\mathrm{c}}-\mathrm{NI}$ & 11 & $3.73(0.79)$ & $3.55(1.44)$ & $0.001 * *$ & 0.76 \\
\hline Encouragement for $\mathrm{PA}^{\mathrm{c}}-\mathrm{FI}$ & 23 & $0.96(1.11)$ & $1.52(1.53)$ & & $0.056^{\dagger}$ \\
\hline Encouragement for healthy eating-NI & 11 & $3.18(0.87)$ & $3.00(1.18)$ & $0.009 * *$ & 0.70 \\
\hline Encouragement for healthy eating-FI & 23 & $1.61(1.37)$ & $1.78(1.20)$ & & 0.65 \\
\hline \multicolumn{6}{|l|}{ Mental health } \\
\hline Depression-NI & 11 & $6.73(6.87)$ & $4.36(5.52)$ & 0.48 & 0.07 \\
\hline Depression-FI & 23 & $8.26(4.92)$ & $5.65(4.67)$ & & $0.004 * *$ \\
\hline Anxiety-NI & 10 & $3.5(4.06)$ & $3.30(6.22)$ & 0.49 & 0.80 \\
\hline Anxiety-FI & 19 & $7.16(6.16)$ & $4.84(5.35)$ & & $0.004 * *$ \\
\hline
\end{tabular}

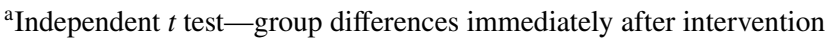

${ }^{\mathrm{b}}$ Sensitivity analyses-participants with normal body mass index (BMI) excluded

'PA: physical activity

${ }^{\dagger}$ Approximating statistical significance

*Statistically significant difference between groups after intervention, $p<0.05$

** Statistically significant difference between groups after intervention, $p<0.01$

household size, all factors that have been shown to affect program results [64]. Also, the groups did not differ in nativity or length of residence in the U.S., factors that presumably could have played a role in the response to immigration activities, nor in baseline depression and anxiety levels. However, the group living farther from the IDC was more likely to be employed and less likely to engage in healthy behaviors (eating greens, walking) and to perceive social support for healthy eating and physical activity.
Our quantitative analyses indicate that the Far-IDC group benefited more from the health promotion program, but these results need to be interpreted with caution since the near-IDC group already walked more, consumed more vegetables, and perceived more social support for healthy eating and physical activity at baseline. The lack of statistically significant improvement in the latter group may very well be due to an initial higher baseline (plateau effect). Still, this would not explain the opposite trends in perceived support 
Table 3 Themes derived from focus group discussion and key informant interview

Themes Summaries and supporting quotes

Theme 1: High program attrition was associated with news of increased ICE activity

Theme 2: News of increased ICE activity was associated with sadness, fear, anxiety and stress
The fear of detention and a desire to be invisible made individuals reluctant to attend the intervention. The CHW stated that individuals were no longer answering their phone calls and that one participant refused to walk the one block to attend the weekly meetings

"One lady lives only one block from the church but we have to pick her up to bring her to the class and then drop her because she is afraid they will stop her if she walks to the class". (KII, referring to an undocumented participant)

When asked whether or not they thought immigration activity affected attendance rates the group's response was "Yes, I think it affected a lot".

When asked why, the response was:

"Because of everything that is happening right now, because of fear, one is afraid to go out. And just like she said, going out and not knowing if you'll ever come back home"

Participants expressed an increase in their anxiety level when the news came around that arrests were happening in the state of California. They feared separation from family members or arrest. Words used to describe their circumstances included "sadness, anxiety, depression, horror, fear, worry, inability to sleep, insecurity, racism":

"Unfortunately we are living in a situation that moms drop off their children but they don't know if they are going to pick them up or they are riding an ICE bus. You never know; that's the reality everyone is living here"

"So when the family has fear, the wife doesn't know if her husband is coming back home or vice-versa or who is going to take care of the children if they don't come back. Are they going to be foster children"?

News and sights of increased ICE activity were associated with heightened anxiety, stress and sadness. The very presence of ICE vehicles seemed to be a constant reminder of the fragility of their circumstances and their lack of control over these, making matters worse:

"There is stress in the community, there is worry"

"It makes one sad, because ... Ay! I don't know... I don't know but it's ugly. What has been happening lately is ugly because... maybe in the past the same was happening but things were not this close, as tangible. So one doesn't even know what to think or what to say because what is happening is very sad".

"The detention center ... is the biggest one from the whole country full of immigrants... When we see that ICE bus, we are afraid. People say there is ICE in that place, but it is normal here. When I pick up my daughter at 2:00 pm the bus comes from [street name] and then goes to [street name] and I drive behind the bus and I know it is coming from the detention center and that is a normal thing to see ... If you go all the way of [street name] you can see the vans from ICE".

Participants also expressed sadness due to the realization of the ripple effect of ICE related news in their neighborhood. Because the community is close, the plight of others locally and in other communities seemed to affect all Latinos, whether or not they were documented or feeling at risk for themselves. Also, undocumented individuals opted to not stand for their rights due to fears:

"So as you see something happened with a person from church, but at the same time your neighbour has a relative in the same situation, how do you think the community feels"?

"A brother from church got in an accident; someone crashed his truck which he used for work. The person who hit the truck from the back is legal. So when they tried to solve the problem they realized that the brother from church is not legal, and because of the fear, our brother from church told the person 'It's okay. Just leave'. He preferred to call us Sunday night to ask for a ride, and call the car dealer to get in debt because he needs a truck. So, those situations are affecting the community and it is sad and difficult".

"It's not only affecting another person's family but me too, because it happened to a friend, and then a person from church, and a relative from the neighbour who lives one block away from my house, so it affects the community in general. We cannot be indifferent. Over here what happened in Texas affects us, what happened in Ohio affects us, what happened in Mississippi where they went into that factory and took mothers who were unable to pick up their children, that too affects the community; it still affects us".

"Sadly this affects the whole family because we are affected too, our friends, our coworkers, our relatives" 
Table 3 (continued)

Themes
$\begin{aligned} & \text { Theme 3: News of increased ICE activity led to } \\ & \text { reduced mobility among Latinos }\end{aligned}$

reduced mobility among Latinos

Theme 4: News of ICE activity was associated with a dramatic decrease in local retail and commercial activity

Theme 5: Suggested solutions included providing participants with tools and resources for self-protection, and spreading the word about their plight
Summaries and supporting quotes

Participants mentioned that they were no longer going out and walking as much as they used to before the news of increased ICE activity. Instead they spent the minimum amount of time outside, in public, and remained sheltered mostly at home

"I prefer to drop off my kid and stop going to other places to not expose myself, because I want to have the opportunity to pick up my kid and come back to our home".

"I didn't want to go to the store. As we say 'just go fast, in and out', as if we try to avoid attacks to our community. That's how one feels intimidated about doing some activities or visiting some places. So you end up deciding that it's better to stay home"

Participants also felt that there was a drastic change in the retail industry of the town, with very few individuals shopping, especially on the day that news arrived of a major raid in the country. Stores, town areas and parking lots that were previously busy and full were now deserted:

"This is not only affecting markets, but also churches. I have seen empty benches, people are afraid to go somewhere and get detained, right? This is not only affecting our community but the businesses too: because if there's no people there is no consumption; if there's no consumption there's no sale. So many people are affected"

"There were always a lot people in the markets, many Latinos came to buy on Wednesday because it's the day of special offers, but we noticed that after all the immigration changes every time less and less people are coming because there is fear in the community"

"I went to the market yesterday and before, you didn't find parking; I used to look for parking far from the store. Sometimes they didn't have enough carts. And I noticed yesterday that it is not the same"

Participants felt helpless as they observed the changes happening around them and requested skills and legal help to better equip them to protect themselves should they need to stand up for their rights

"I think that it would be good to have those types of workshops that are a bit different and would teach us about our rights, what you can do in different cases, and more info about this topic. I think I would feel more confident to go out, knowing my rights and knowing what to do. Because sometimes there are many people that can help us, but don't know how to reach us".

"A workshop where they can teach us our rights, to know what laws protect us-maybe someone who can help us not feel intimidated with the situation that is happening right now".

"The fact that we as Latinos are strong and resilient in spite of all the difficulties-we try to keep moving forward-doesn't mean we don't have feelings. It is good that they can bring programs and talk about mental health but that is not solving the big problem the community is facing"

"We need to stand for ourselves so that they can hear us and know how our community is living in this moment"

"I am not sure what the impact of our voice in this program regarding this situation is but if they can canalize our concerns so we can have peace and tranquility..."

The focus group discussion (FGD) was conducted with 10 participants and the key informant interview (KII) with one bilingualpromotora who led the program. All quotes are from the FGD unless followed by the letters "KII". Quotes are translations of theoriginal Spanish statements.

for healthy behaviors between these groups. Indeed, despite the Near-IDC group initially reporting more family support and engagement in healthy behaviors than the Far-IDC group, the social support they initially had for healthy behaviors dwindled by program completion. It is possible that collective stress may have caused a priority shift, which would be in keeping with Maslow's hierarchy of needs model [65].

Dropouts from the Near-IDC group were all foreign-born, perceived less family encouragement for healthy behaviors, and reported eating fewer meals per day at baseline. Although not direct indicators of immigration and legal status, the last two characteristics have been associated with acculturation: studies have shown that foreign-born Latinas tend to be healthier, while those living in the U.S. longer tend to be more obese, engage in less physical activity, and have more meals/snacks per day [66-68]. Based on eating pattern, we suspect then that the dropout group included more undocumented and/or fewer acculturated Latinas, which may explain why the only participant who reported living less than 6 years in the U.S. was among the dropouts. This may be an indication of the degree of fear or distress that undocumented participants experienced. Unfortunately, CHWs were unable to reach the dropouts who, though initially highly engaged, did not answer phone calls or even 
respond to personal visits by our CHWs. However, baseline surveys indicated that most were foreign-born, and our qualitative data suggest that this occurred due to extreme fear of being identified and deported.

Moreover, according to our qualitative findings, news of ICE arrests of fellow Latinos seems to have destabilized the morale of both documented and undocumented Latinas living near the immigration detention center, and had negative physical, emotional, and financial impacts [22]. These fears took a distinct toll on participants who initially had high attendance and overall readiness to engage with the program. Even those who remained in the program reported sadness, anxiety, and stress related to the immigration raids and felt that there was a demoralizing reduction in local social activities. The authors learned that ICE raids caused the entire local Latino community to "hunker down" following the news. Interestingly, participants described a phenomenon that the entire country would experience months later during the COVID-19 pandemic: eerily quiet public spaces, drastic reduction in economic activity, and "sheltering-in-place" of entire extended families. Furthermore, this change in circumstances also heightened participants' desire for resources to protect/defend themselves from potential threats to their families.

While anxiety and depression were measured and results suggest a pattern in line with the interpretation presented in this paper, the authors were unable to assess stress via a validated scale and to gauge the extent to which Near-IDC participants experienced continuous traumatic stress. However, feelings and behaviors associated with CTSD, such as hypervigilance, stress, worry, perceived vulnerability, and lack of control, were evident in the qualitative data. "Immigration stress" is one of the policy-related social determinants of health-conditions "in which people are born, grow, live, work and age" - that have been associated with negative health consequences $[69,70]$. In this study it seems plausible that all participants would have experienced some degree of traumatic stress regardless of legal status: some undocumented participants dropping out altogether, others choosing to complete the program but remaining hypervigilant and experiencing increased stress, and still others with authorized "legal" status being negatively emotionally affected and benefiting less from the program.

One of our study limitations is the lack of information about, and thus inability to control for, our participants' legal status. However, no statistically significant baseline differences in the variables we used as proxies were seen between the Near-IDC and Far-IDC groups. We also did not control for social support or employment differences between groups, and no focus group discussion was conducted in the Far-IDC group. However, FGD comments were specific to the area where Near-IDC participants live (the sight of the bus driving by, the drastic reduction in number of cars parked in the shopping areas). Furthermore, the Far-IDC group did not have the same degree of attrition. Having both self-reported and biometric measures as well as an affected and a comparison group were strengths of our study, as was the mixed methods triangulation used to further explore this phenomenon.

Healthcare professionals and policy-makers should be aware of Latina patients' complex lives being significantly affected by the proximity to a detention center regardless of their legal status. Moreover, providing education and resources to Latinas living in these communities and equipping them to handle the emotional trauma and fear of possible legal confrontations would be a welcome service. Future research should expand on the potential impact of stress related to ICE activities and the continuous traumatic stress associated with it to determine the health ramifications on this high-need population. While expansion of IDCs may be economically beneficial to some, the health and prevention needs of the local population should remain an important consideration. The results of such studies may provide a more accurate estimate of the true cost of hosting a detention center in the midst of a Latino community.

\section{New Contribution to the Literature}

This publication adds to the literature by shedding light on the unanticipated negative impact of immigration policies and location of immigration detention centers on Latinas, a group already struggling with high rates of health disparities. Latinas living in these settings, regardless of their legal status, are susceptible to added stress and anxiety and seem to benefit less from much needed health interventions. The realities that prevail in communities where IDCs are often placed should be understood and further assessed. Not only should addressing the mental health stressors be part of a regular healthcare protocol, but also prevention services should be promoted more aggressively. Steps should also be taken to provide these vulnerable populations with resources and legal support. Lastly, our results seem to indicate that health and politics are not separate, and that the reality of Latinos' health disparities cannot be addressed by offering health or prevention services that ignore immigration policies.

Supplementary Information The online version contains supplementary material available at https://doi.org/10.1007/s10903-021-01219-2.

Acknowledgements This research project was funded by the Ardmore Institute of Health. Thanks to the pastors who allowed us to use their church building for our program, and to the promotoras for their dedication to enhancing the health of their fellow community members. Lastly, we are grateful for the women who were willing to share their honest insight and experiences. Names of individuals acknowledged and of streets have been purposefully withheld. 


\section{Declarations}

Conflict of Interest The authors declare that they have no conflict of interest.

Ethical Approval Ethical approval for this study was obtained from the Loma Linda University Institutional Review Board (IRB \#5180068).

\section{References}

1. American Diabetes Association: Statistics. Examine the facts. Alexandria, VA: American Diabetes Association. 2020. Retrieved from https://www.diabetes.org/resources/statistics

2. Centers for Disease Control and Prevention: National Diabetes Statistics Report, 2017. Atlanta, GA: Centers for disease control and prevention, US Department of health and human Services. 2017. Retrieved from https://www.cdc.gov/diabetes/library/featu res/hispanic-diabetes.html

3. Aguayo-Mazzucato $\mathrm{C}$, et al. Understanding the growing epidemic of type 2 diabetes in the Hispanic population living in the United States. Diabetes Metab Res Rev. 2019;35(2):e3097. https://doi. org/10.1002/dmrr.3097.

4. Tai DBG, et al. The disproportionate impact of COVID-19 on racial and ethnic minorities in the United States. Clin Infect Dis. 2020. https://doi.org/10.1093/cid/ciaa815.

5. Department of Public Health: Covid-19. Covid-19 race and ethnicity data. 2020. Retrieved from https://www.cdph.ca.gov/Progr ams/CID/DCDC/Pages/COVID-19/Race-Ethnicity.aspx

6. Townsend MJ, et al. Commentary: COVID-19 and obesity: exploring biologic vulnerabilities, structural disparities, and weight stigma. Metabolism. 2020;110:154316. https://doi.org/ 10.1016/j.metabol.2020.154316.

7. Thakur N, et al. The structural and social determinants of the racial/ethnic disparities in the U.S. COVID-19 Pandemic. What's Our Role? Am J Respir Crit Care Med. 2020;202(7):943-9. https://doi.org/10.1164/rccm.202005-1523PP.

8. Tai DBG, et al. The disproportionate impact of COVID-19 on racial and ethnic minorities in the United States. Clin Infect Dis. 2020;72:703-6. https://doi.org/10.1093/cid/ciaa815.

9. S. Department of Health and Human Service: Office of minority health. Diabetes and hispanic Americans: Minority population profiles. Washington, DC: U.S. Department of Health and Human Services. 2017. Retrieved from https://minorityhealth.hhs.gov/ $\mathrm{omh} /$ browse. aspx $? \mathrm{lvl}=4 \&$ lvlid $=70$

10. Katsoulis M, et al. Obesity during the COVID-19 Pandemic: cause of high risk or an effect of lockdown? A population-based electronic health record analysis in 1958184 Individuals. medRxiv [Preprint]. 2020. https://doi.org/10.1101/2020.06.22.20137182

11. Rodriguez-Diaz CE, Guilamo-Ramos V, Mena L, et al. Risk for COVID-19 infection and death among Latinos in the United States: examining heterogeneity in transmission dynamics. Ann Epidemiol. 2020;52:46-53. https://doi.org/10.1016/j.annepidem. 2020.07.007.

12. Ritchie ND, et al. Effect of the national diabetes prevention program on weight loss for English- and Spanish-speaking Latinos. Am J Health Promot. 2018;32(3):812-5. https://doi.org/10.1177/ 0890117117698623.

13. Held ML, Nulu S, Faulkner M, et al. Climate of fear: provider perceptions of Latinx immigrant service utilization. J Racial and Ethnic Health Disparities. 2020;7:901-12. https://doi.org/10. 1007/s40615-020-00714-w.
14. Novak NL, Geronimus AT, Martinez-Cardoso AM. Change in birth outcomes among infants born to Latina mothers after a major immigration raid. Int J Epidemiol. 2017;46(3):839-49.

15. Pinedo M. The impact of deportation policies on the substance using behaviors of US-citizen Latinos. Int J Drug Policy. 2020;75:102605.

16. Rhodes SD, et al. The impact of local immigration enforcement policies on the health of immigrant hispanics/latinos in the United States. Am J Public Health. 2015;105(2):329-37.

17. Hacker $\mathrm{K}$, et al. The impact of immigration and customs enforcement on immigrant health: perceptions of immigrants in Everett, Massachusetts, USA. Soc Sci Med. 2011;73(4):586-94.

18. Sanchez GR, Juárez M. Fear by association: perceptions of antiimmigrant policy and health outcomes. J Health Polit Policy Law. 2017;42(3):459-83.

19. Martinez O, et al. Evaluating the impact of immigration policies on health status among undocumented immigrants: a systematic review. J Immigr Minor Health. 2015;17(3):947-70.

20. Bruzelius E, Baum A. The mental health of hispanic/latino Americans following national immigration policy changes: United States, 2014-2018. Am J Public Health. 2019;109(12):1786-8.

21. Jordan M. Families split by border endure wait in Anguish. NY Times. 2018;167(58073):1-10.

22. Altman CE. Immigrant policies as health policies: State immigrant policy climates and health provider visits among U.S. immigrants. SSM Population Health. 2020;10:100559. https://doi.org/ 10.1016/j.ssmph.2020.100559.

23. Eskenazi B, et al. Association of perceived immigration policy vulnerability with mental and physical health among US-born latino adolescents in California. JAMA Pediatr. 2019;173(8):744-53.

24. Lopez WD, et al. Health implications of an immigration raid: findings from a latino community in the Midwestern United States. J Immigr Minor Health. 2017;19(3):702-70.

25. Philbin MM, et al. State-level immigration and immigrant-focused policies as drivers of Latino health disparities in the United States. Soc Sci Med. 2018;199:29-38.

26. Watch Network: the issues. Immigration detention 101. 2020. Retrieved from https://www.detentionwatchnetwork.org/issues/ detention-101

27. McGeever K. correctional facility establishments and neighborhood housing characteristics. Sociologic Perspec. 2019;62(3):383-401.

28. City-data.com. Retrieved from http://www.city-data.com/zips/ 77032.html

29. City-data.com. Retrieved from https://www.zipdatamaps.com/ 78840

30. City-data.com. Retrieved from http://www.city-data.com/zips/ 07201.html

31. City-data.com. Retrieved from https://www.zipdatamaps.com/ 87102

32. City-data.com. Retrieved from http://www.city-data.com/zips/ 92301.html

33. Mint Press News. Retrieved from https://www.mintpressnews. com/wp-content/uploads/2018/08/victorville-prison-1533226807e1533226888653.jpg

34. Garfin DR, et al. Exposure to rapid succession disasters: a study of residents at the epicenter of the chilean bio bio earthquake. J Abnorm Psychol. 2014;123(3):545-56.

35. King RS, Mauer M, Huling T. An analysis of the economics of prison siting in rural communities. Criminol Public Policy. 2004;3(3):453-80.

36. Michels H: Bill would end state's contract with for-profit 660 -bed prison. Montana standard (The Butte, MT). 2017. Retrieved from https://mtstandard.com/news/state-and-regional/govt-and-politics/ 
bill-would-end-state-s-contract-with-for-profit-/article_abaec9596e66-509b-90a5-007d647ca135.html

37. Kilburn J, et al. A paper tiger on chestnut lane: the significance of NIMBY battles in decaying communities. Urbanities. 2014;4(2):3-20.

38. Broto VC, et al. Stigma and attachment: performance of identity in an environmentally degraded place. Soc Nat Resour. 2010;23(10):952-68.

39. Doshi M, Lopez W, et al. Impact of anti-immigrant rhetoric and policies on frontline health and social service providers in Southeast Michigan, U.S.A. Health Soc Care Community. 2020;28:2004-12.

40. Ryo E, et al. Beyond the walls: the importance of community contexts in immigration detention. Am Behav Sci. 2019;63(9):1250-75.

41. Saadi A, et al. Assessment of perspectives on health care system efforts to mitigate perceived risks among immigrants in the United States: a qualitative study. JAMA Netw Open. 2020;3(4):e203028. https://doi.org/10.1001/jamanetworkopen2020;3028.

42. Plevin R: Adelanto approves GEO plan to expand capacity at California immigration detention center. 2020. The Desert Sun

43. Immigration Defense Project/Immigration raids. 2020. Retrieved from https://www.immigrantdefenseproject.org/raids/

44. Craig W: Threat of ICE Raids can cause PTSD, mental health experts said. 2019. Retrieved from https://news.yahoo.com/threatice-raids-cause-ptsd-231043414.html

45. Breslau N. Gender differences in the sensitivity to posttraumatic stress disorder: An epidemiological study of urban young adults. J Abnorm Psychol. 2007;116(3):607-11.

46. Daniel Taylor: When Children Face Continuous Traumatic Stress Disorder. The Philadelphia Inquirer. May 25, 2011. Retrieved from https://www.inquirer.com/philly/news/nation_world/20110 525_When_children_face_continuous_traumatic_stress_disorder. html

47. Kaminer D, et al. Continuous traumatic stress as a mental and physical health challenge: case studies from South Africa. J Health Psychol. 2018;23(8):1038-49. https://doi.org/10.1177/ 1359105316642831.

48. Eagle G, Kaminer D. Continuous traumatic stress: expanding the lexicon of traumatic stress. Peace and Conflict Peace Confl. 2013;19(2):85-99.

49. Rosenberg J: The effects of chronic fear on a person's health. Neuroscience Education institute (NEI). 2017. Congress

50. Higson-Smith C. Counseling torture survivors in contexts of ongoing threat: Narratives from sub-Saharan Africa. Peace Confl. 2013;19(2):164.

51. Torres L, Taknint JT. Ethnic microaggressions, traumatic stress symptoms, and Latino depression: a moderated mediational model. J Couns Psychol. 2015;62(3):393-401. https://doi.org/10. 1037/cou0000077.

52. California Department of Public Health. Programs: Center for Health Statistics and Informatics: County Health Status Profiles. Sacramento: CA. 2019. https://www.cdph.ca.gov/programs/chsi/ pages/county-health-status-profiles.aspx.

53. U.S. Census Bureau: U.S. Department of Commerce. Economics and Statistics Administration. U.S. Census Bureau. The Hispanic Population. 2010. Retrieved from https://www.census.gov/popul ation/www/cen2010/glance/2010CensusBriefs.html

54. Tory S: If you don't want us, tell us to go back: the making of a California prison town. High Country News. 2017. Retrieved from https://www.hcn.org/issues/49.8/how-adelanto-came-to-host-calif ornias-biggest-immigration-detention-facility

55. Charmaz K. Constructing grounded theory: a practical guide through qualitative analysis. London: Sage Publications; 2006.

56. Hauslohner A: The Washington Post. ICE agents raid 7 work sites in Mississippi, arrest 680 people in largest single-state immigration enforcement action in U.S. history. 2019. Retrieved from https://www.washingtonpost.com/immigration/ice-agentsraid-miss-work-sites-arrest-680-people-in-largest-single-stateimmigration-enforcement-action-in-us-history/2019/08/07/801d5 cfe-b94e-11e9-b3b4-2bb69e8c4e39_story.html

57. Braun V, Clarke V. Using thematic analysis in psychology. Qual Res Psychol. 2006;3:77-101. https://doi.org/10.1191/1478088706 qp063oa.

58. Craig CL, Marshall AL, Sjöström M, et al. International physical activity questionnaire: 12 -country reliability and validity. Med Sci Sports Exerc. 2003;35(8):1381-95. https://doi.org/10.1249/ 01.MSS.0000078924.

59. Kroenke K, Spitzer RL, Williams JB. The PHQ-9: validity of a brief depression severity measure. J Gen Intern Med. 2001;16(9):606-13. https://doi.org/10.1046/j.1525-1497.2001. 016009606.x.

60. Löwe B, et al. Validation and standardization of the generalized anxiety disorder screener (GAD-7) in the general population. Med Care. 2008;46(3):266-74. https://doi.org/10.1097/MLR.0b013 e318160d093.

61. Verbi Software Consult: Sozialforschung GmbH. MAXQDAplus (Version 12) [Computer software]. 2015. Berlin, Germany

62. Flaherty A, Ebbs S: Trump confirms ICE raids set for Sunday as cities, advocates brace to respond. 2019. Retrieved from https:// abcnews.go.com/Politics/cities-brace-ice-deportation-raidstrump-threats-spread/story?id $=64268222$

63. CBS local news. 2019. Retrieved from https://losangeles.cbslocal. com/2019/05/22/hundreds-of-asylum-seekers-being-released-insan-bernardino/

64. McCurley JL, Gutierrez AP, Gallo LC. Diabetes prevention in U.S. hispanic adults: a systematic review of culturally tailored interventions. Am J Prev Med. 2017;52(4):519-29. https://doi. org/10.1016/j.amepre.2016.10.028.

65. Maslow AH. Motivation and personality. New York: Harper \& Row; 1970.

66. Yellow Horse AJ, Santos-Lozada AR. Foreign-born hispanic women's health patterns in allostatic load converge to U.S.-born hispanic women at a slower tempo compared with men. Womens Health Issues. 2019;29(3):222-30. https://doi.org/10.1016/j.whi. 2019.01.001.

67. Bekelman TA, Johnson SL, Taylor CA. Differences in diet quality and snack intakes among non-hispanic white and mexican american adolescents from different acculturation groups. J Racial Ethn Health Disparities. 2020;7(6):1090-9. https://doi.org/10.1007/ s40615-020-00732-8.

68. Commodore-Mensah Y, Ukonu N, Obisesan O, Aboagye JK, Agyemang C, Reilly CM, Dunbar SB, Okosun IS. Length of residence in the United States is associated with a higher prevalence of cardiometabolic risk factors in immigrants: a contemporary analysis of the national health interview survey. J Am Heart Assoc. 2016;5(11):e004059. https://doi.org/10.1161/JAHA.116.004059. PMID:27815269;PMCID:PMC5210341.

69. Marmot M. Social determinants of health inequalities. Lancet. 2005;365(9464):1099-104. https://doi.org/10.1016/S01406736(05)71146-6.

70. Sanchez M, et al. Immigration social capital. Stress among recent latino immigrants: the protective role of social support and religious. Soc Work Public Health. 2019;34(4):279-92. https://doi. org/10.1080/19371918.2019.1606749.

Publisher's Note Springer Nature remains neutral with regard to jurisdictional claims in published maps and institutional affiliations. 